\title{
El Ethos calvinista y el capitalismo moderno
}

\author{
(Una reflexión crítica sobre la tesis de Max Weber)
}

I. INTRODUCCIÓN: MAX WEBER, SOCIÓLOGO DE LA ACCIÓN SOCIAL

Max Weber, entre otras cosas, puede ser considerado uno de los sociólogos más destacados de la acción social '.

En su obra póstuma «Economía y Sociedad» áfirma que «Debe entenderse por sociología (...): una ciencia que pretende entender, interpretándola, la acción social para que de esa manera explicarla causalmente en su desarrollo y efectos. Por acción debe entenderse una conducta humana (bien consista en un hacer externo o interno, ya en un omitir o permitir) siempre que el sujeto o los sujetos de la acción enlacen a ella un sentido subjetivo. La acción social, por tanto, es una acción en donde el sentido mentado por su sujeto o sujetos está referido a la conducta de otros, orientándose por ésta en su desarrollo» ${ }^{2}$. Y un poco más adelante Weber se expresa en estos términos: "La acción social (incluyendo tolerancia $u$ omisión) se orienta por las acciones de otros, las cuales pueden ser pasadas, presentes o esperadas como futuras (venganzas por previos ataques, réplica a ataques presentes, medidas de defensa frente a ataques futuros)» ${ }^{3}$.

La acción humana y social, pues, tiene un significado subjetivo en el que está implicado una referencia a otros. Tiene que haber un sentido propio en la acción dirigida a otros. Por eso Weber indica que no todo contacto con los hombres es una acción social. Puede ser un fenómeno casual, mecánico y sin sentido interior. Tampoco puede ser considerada como accion social una acción similar de muchos individuos. Ni lo es la acción de un sujeto «influido» por la conducta de otros, condicionado por la acción de la «masa», ya que no se da una relación significativa entre la conducta de dicho sujeto y su partici-

1. Otros son Pareto, Parsons, Touraine, etc, etc.

2. MaX Weber, Economia y sociedad, F.C.E. México, 1969. t. I, 5.

3. MAX WeBER, o.c., t. I., 18. 
pación en la «masa» ${ }^{4}$. En estos casos, como en la imitación reactiva (tratada por G. Tarde), no se da una orientación con sentido de la propia acción por la ajena" '. Por tanto, lo fundamental de la acción, como dice J. Freund, es la relatividad significativa con respecto al comportamiento ajeno. Incluso se puede dar el caso de que el sujeto-actor no tenga conciencia del verdadero sentido de su conducta orientada de acuerdo con el projimo ${ }^{6}$. En definitiva, una actividad social «se caracteriza por el hecho de que el agente regula su conducta de acuerdo con la esperanza de que los demás se comportarán de una cierta manera, es decir, que encuentra allí una razón favorable o una oportunidad de llevar a buen término la acción considerada» ${ }^{6 \mathrm{~b}}$. La «oportunidad», pues, indica que los hombres van a sujetar su comportamiento, casi seguro o muy probablemente, a la normativa, a la costumbre o los valores vigentes. Esta oportunidad o probabilidad objetiva es la que posibilita la acción social y la permanencia de una estructura social. Y esta actividad social o comunitaria es el dato central o constitutivo de la sociología tal como Weber la concibe ${ }^{7}$.

Max Weber clasifica los tipos de acción social distinguiendo entre la «acción racional con arreglo a fines», la «acción racional con arreglo a valores», la "acción afectiva o emocional» y la «acción tradicional». En la «acción racional con arreglo a fines», el actor concibe con claridad el fin y elige los medios para realizarlo ${ }^{8}$. Así las operaciones de un ingeniero para construir un puente. Este tipo de acción en cuanto que es el que posee la máxima evidencia racional ${ }^{9}$ goza de una relevancia especial para la sociología comprensiva. «Su evidencia se manifiesta en que se funda en reglas generales de la experiencia, no para someterse ciegamente a ellas o formar un criterio intangible, sino para ordenar la previsión lo más racionalmente posible» ${ }^{10}$. La «acción racional con arreglo a valores» está determinada «por la creencia consciente en el valor - ético, estético, religioso o de cualquier otra forma como se le interpretepropio y absoluto de una determinada conducta, sin relación alguna con el resultado, o sea puramente en méritos de ese valor (...) es siempre (en el sentido de nuestra terminología) una acción según «mandatos» o de acuerdo con «exigencias» que el actor cree dirigidos a él ( $y$ frente a los cuales el actor se cree obligado)» ${ }^{10 b}$. Es una acción que se inspira en la convicción del sujeto-actor

4. Cf. MAX WEBER, o.c., t. I., 19.

5. Cf. MAX Weber, o.c., t. I., 19.

6. J. Freund, La Sociología de Max Weber, Península, Barcelona 1973, 106.

7. «La sociología en modo alguno tiene que ver solamente con la acción social; sin embargo, ésta constituye (para la clase de sociooogía aquí desarrollada) el dato central, aquél que para ella, por decirlo así, es constitutivo», MAX WEBER, o.c., t. I., 20.

8. Cf. MAX Weber, o.c., t. I., 20 y 21.

9. La racionalidad tal como aquí la entiende Weber, se refiere al resultado del desarrollo científico y la especialización técnica de la civilización occidental. «A esta forma de la «acción racional con arreglo a fines» es a la que corresponde como su específica forma teórica la ciencia, susceptible de aplicación tecnológica». C. MoYA, «Sociólogos y Sociología». Siglo XXI, México $1970,132$.

10. J. FreUnd, o.c., 96. 
independientemente de las consecuencias que se puedan preveer. Se caracteriza por una coherencia entre la convicción y la manera de proceder. Y es aquí donde reside su racionalidad. El actor actúa racionalmente al aceptar todos los riesgos, no para obtener un resultado extrínseco, sino para permanecer fiel a la idea que se forja»" "Como la misma definición de Weber indica, las formaciones intelectuales que corresponden a este tipo de acción son la religión, la ética y la ideología en general.

Se comprende con todo esto, que, con la «Racionalidad», en una acciónr motivada, Weber se refiera, la mayoría de las veces a la concordancia entre los medios y los fines deseados. En el primer caso aludido, el sujeto-actor evalúa racionalmente las consecuencias implicadas en la elección de los medios elegidos para conseguir el fin. En el segundo caso, el sujeto-actor «persigue de manera consciente un objetivo superior sin «reparar en el precio» ${ }^{12}$.

La «acción afectiva o emotiva» está «determinada por afectos y estados sentimentales actuales (...) puede ser una reacción sin trabas a un estímulo extraordinario, fuera de lo cotidiano" ${ }^{13}$. Como dice R. Aron, está determinada por el estado de conciencia o el humor del sujeto.

El tipo de «acción tradicional» «a menudo no es más que una oscura reacción a estímulos habituales, que se desliza en la dirección de una actitud arraigada. La masa de todas las acciones cotidianas, habituales, se aproxima a este tipo...» ${ }^{14}$. Está, pues, determinada por hábitos, costumbres y creencias que se han convertido en una «segunda naturaleza». Es la acción propia de la rutina colectiva «en la que la racionalidad subjetiva parece disuelta en el automatismo mecánico de la costumbre popular» ${ }^{15}$. En este tipo de acción, el sujeto-actor «no necesita representarse un fin, ni concebir un valor, ni sentirse agitado por una emoción; obedece simplemente a los reflejos afirmados por una prolongada práctica» ${ }^{16}$. Por último, no hay que olvidar que Weber lo que ha hecho es elaborar una tipología ideal de la acción social. Por ello es lógico que afirme: «Muy raras veces la acción, especialmentè la acción social está exclusivamente orientada por uno u otro de estos tipos. Tampoco estas formas de orientación pueden considerarse en modo alguno como una clasificación exhaustiva, sino como puros tipos conceptuales, construidos para fines de la investigación sociológica, respecto a los cuales la acción social se aproxima más o menos o, lo que es más frecuente, de cuya mezcla se compone» ${ }^{17}$. 238.

11. R. Aron, Las etapas del pensamiento sociológico, Siglo XX, Buenos Aires, 1970, t. II,

12. A. Giddens, Politica y Sociología en Max Weber, Alianza, Madrid 1976, 64-65.

13. MAX WEBER, o.c., t. I., 20.

14. MAX Weber, o.c., t. I., 20.

15. C. MOYA, o.c., 131.

16. R. ArON, o.c., t. II, 238-239.

17. MAX Weber, o.c., t. I., 21. 
Teniendo en cuenta la concepción de la acción social de Weber aquí expuesta, se comprende que, en términos generales, su construcción teóricosistemática entienda a la sociedad como «un complejo de interrelaciones humanas caracterizado por la conducta significativa de una pluralidad de actores" ${ }^{18}$. También se comprende que, para él, lo colectivo no constituye una realidad por sí, ya que el sujeto-actor es el auténtico portador del comportamiento significativo. El sentido implica una conciencia individual.

Desde luego, esta tipología le sirve a Weber para interpretar la época contemporánea, como una época de racionalización creciente, donde predomina el primer tipo de acción estudiada. Esta racionalidad se manifiesta en la empresa económica y en la organización burocrática. Incluso, comparativamente, Weber observa que cierto grado de racionalidad detectado en otras culturas no ha tenido la fuerza interna y expansiva de la de la civilización occidental. Al igual que en su «dinámica social», A. Comte defendía la idea de que la sociedad industrial era, de alguna manera, el fruto del «estado positivo» de la conciencia humana que tenía una vocación universal, esto es, era el futuro del grupo humano; y al igual que $\mathrm{H}$. Spencer, con su concepción «lamarckiana» del evolucionismo social veía en el horizonte de la humanidad una sociedad cada vez más compleja en su estructura, pero cada vez más integrada funcionalmente, Max Weber veía en su sociología histórica, la historia de la humanidad como un proceso progresivo de racionalización de la actividad social y de sus implicaciones estructurales. Y como se va a reflejar en el tema fundamental de este trabajo, la sociología comprensiva de Weber, de alguna manera, «es un gigantesco esfuerzo por desentrañar el papel de la razón en la historia social del hombre» ${ }^{19}$.

Partiendo de la noción weberiana de la acción social, se comprende que su sociología la denomine "Comprensiva». En el dominio de los fenómenos naturales expresamos mediante proposiciones de índole matemática las regularidades que aprehendemos mediante la observación. Explicamos los fenómenos mediante proposiciones que la experiencia nos confirma. En cambio, el hombre aparece dotado de conciencia y su conducta presenta una inteligibilidad interior, una trama inteligible que las ciencias del hombre tienen que desvelar y aprehender. El problema de la comprensión del sentido, deriva de la estructura teleológica de la acción humana; ella se desarrolla con vistas a un fin. La comprensión de la acción del hombre debe captar su motivo, entendiendo por él «la conexión de sentido que para el actor o el observador aparece como el «fundamento» con sentido de una conducta» ${ }^{20}$. Está claro que las acciones humanas presentan una inteligibilidad interior, un significado subjetivo. El hombre actúa motivado por las necesidades y un sentido que le dan

18. N.S. TimashefF, «La teoría sociológica», F.C.E., México, 1971, 231.

19. C. MOYA, o.c., 120-121.

20. MAX WEBER, o.c., t. I., 10. 
los valores. Y si queremos explicar las regularidades aprehensibles de la conducta del hombre es muy importante comprender, interpretativamente, el significado de las acciones para el actor en cuestión.

El significado o sentido de la cultura no puede entenderse mediante un sistema de leyes analíticas, como las que instrumentan las ciencias de la naturaleza, debido a que los fenómenos culturales implican una orientación valorativa.

Ahora bien, la interpretación comprensiva debe completarse con la explicación causal, y ello porque la aprehensión de las determinaciones causales es un modo de garantizar validez universal a los resultados. $O$ dicho de otro modo, sólo la causalidad otorga a la investigación comprensiva la categoría de proposición científica. Si la comprensión nos aporta el desciframiento del sentido, ha de ser confirmada por la observación estadística y. la imputación causal. Sólo así podrá la sociología alumbrar proposiciones generales. Y ambos pasos metodológicos se complementan: «la explicación sociológica satisfactoria (...) debe ser a la vez subjetivamente significativa y factualmente probable" ${ }^{21}$. Y esto se refleja en las mismas expresiones que, a veces, utiliza el mismo Weber: «explicación comprensiva», «interpretación causal», etc. Y como nos indica Freund, la combinación de la explicación causal con la comprensión de sentido hace que las relaciones causales sean «relaciones significativas".

Con este planteamiento, Max Weber hizo un notable esfuerzo por superar la oposición entre las ciencias de la naturaleza y las ciencias del espíritu, entre las ciencias «nomotéticas» y las «ideográficas» (Windelband); oposición que se fundamentaba sobre la base de que los fenómenos históricos y sociales son únicos y no se puede generalizar sobre ellos ${ }^{22}$.

Por otro lado, teniendo en cuenta que comprendemos lo singular, la dimensión histórica adquiere en las ciencias del hombre un relieve y un alcance que no pueden tener en las ciencias de la naturaleza. En verdad, se distinguirá en este tipo de ciencia que tiene como objeto de estudio el fenómeno humano dos orientaciones: la histórica y la sociológica; dos orientaciones que desde luego no pueden ignorarse ${ }^{23}$. La propia obra de Weber nos da testimonio de

21. N.S. TIMASHEFF, o.c., 224.

22. "Weber rechazaba parcialmente este punto de vista, ya que consideraba que las categorias científicas podian utilizarse, aunque se apresuraba a anadir que debía utilizarse con cuidado. Por otra parte aceptaba el punto de vista de que, es necesario adoptar tanto una perspectiva subjetiva como una perspectiva objetiva». D. Mitchell, Historia de la Sociologia, t. I. Guadarrama. Madrid, 1973, t. I, 141. Hoy, la separación se debilita y se va dando un acercamiento entre las «ciencias nomotéticas» y las «históricas» y humanas en general. Cf. PIAGET.y otros. "Tendencias de la investigación en las ciencias sociales». Alianza Universidad. Madrid 1976, 96106, y cap. 2 («Problemas generales de la investigación interdisciplinaria y mecanismos comunes»).

23. Una orientación histórica «es decir, hacia la reseña de lo que jamás se verá dos veces, y 
ello. La segunda orientación cobra su forma más nítida en «la teoría general». $\mathrm{Y}$ aunque Weber, teniendo en cuenta la complejidad y dinamismo de los fenómenos culturales e históricos, no fue partidario de las grandes teorias generales, tras el estudio comparativo de las grandes civilizaciones, escribió una especie de teoría general donde precisó acuñaciones conceptuales fundamentales, que componen la primera parte de su obra «Economía y Sociedad».

Por último, debido a que la sociología comprensiva de Weber trata de desvelar el sentido subjetivo de la acción humana y social, es lógico que en ella cobre una relevancia capital el mundo de las ideas, de las convicciones morales y de las creencias religiosas. Como nos recuerdan Berger y Luckmann, «El hombre ocupa una posición peculiar dentro del reino animal. A diferencia de los demás mamíferos superiores no posee ambiente específico de su especie firmemente estructurado por la organización de sus propios instintos» ${ }^{24}$. Los animales «viven en mundos cerrados cuyas estructuras están predeterminadas por el capital biológico de las diversas especies animales» ${ }^{25}$. En cambio, la estructura psico-biológica del ser humano instrumenta un tipo de relación con el mundo que está imperfectamente estructurada. En comparación con los animales superiores, el hombre presenta una organización instintual subdesarrollada, esto es, los impulsos humanos están mucho menos especificados y con una dirección menos concreta. Y esta característica del organismo humano, se basa, según los autores mencionados, en su desarrollo ontogenético. Hay determinados desarrollos del organismo humano que tienen ya lugar en la vida extrauterina (ocurriendo lo contrario en el caso de los animales) ${ }^{26}$. Así el organismo del hombre se sigue desarrollando biológicamente en una vida extrauterina, en la que entabla relación con un determinado ambiente. Ambiente que es tanto natural como cultural. Claro que esta indeterminación constitutiva del hombre va acompañada, con la inteligencia, de una formidable capacidad de invención. Ante una gama de posibilidades, el hombre tendrá que crear sus propias especializaciones y determinaciones, aunque de algún modo, trascendiéndolas siempre. De ahí la enorme plasticidad, capacidad de adaptación e inventiva del género humano. Estas determinaciones vienen a constituir modos culturales de comportamiento. $\mathrm{Y}$ el hombre es un animal cultural porque actúa conforme a las pautas, ideas y valores que él

otra hacia la sociología, es decir, hacia la reconstrucción conceptual de las instituciones sociales y de su funcionamiento. Estas dos orientaciones son complementarias», R. ARON, o.c., t. II, 246 . O dicho de otra manera: cabe hablar de dos explicaciones causales, la histórica y la sociológica. «De acuerdo con los casos, la relación de causalidad es histórica o sociológica. El historiador trata de sopesar la eficacia causal de los distintos antecedentes en una coyuntura única, y el sociólogo procura establecer relaciones de consecución que se repiten o que pueden repetirse», R. ARON, o.c., t. II, 268.

24. Berger y LuCKMAnN, La construcción social de la realidad, Amorrortu, B. Aires, 1972,66 .

25. BERGER Y LUCKMANN, o.c., 67

26. Cf. E. MORIN, «El hombre y la muerte», Kairós, Barcelona 1974, 85 y 86. 
mismo se ha dado, en su interacción con el projimo y el medio. Por ello el mundo animal es el de la inmediatez, el del hombre, el de la conciencia otorgadora de sentido ${ }^{27}$.

Naturalmente el individuo humano nace ya en un medio sociocultural determinado que le procura introyectar, por un proceso de socializacion, un modo y un sentido de actuar: aquel que le permitirá una incardinación mínimamente armónica en la sociedad en que le ha tocado vivir. El hombre, y la sociedad en general, se ven obligados a objetivar el sentido de su acción, pues sin ello no sería posible la comunicación, ni la socialización. El signo viene a ser una objetivación que sirve como indicio de significados subjetivos. $\mathrm{Y}$ el lenguaje es un sistema de signo vocales, a través del cual el hombre y la sociedad expresan sus ideas, creencias y actitudes. El lenguaje gracias a su capacidad de trascendencia espacio-temporal viene a ser depósito objetivo de enormes acumulaciones de significados y experiencias transmisibles a las generaciones venideras.

También es cierto que la sociedad necesita de una «legitimación» cuando intenta transmitir su cultura y el orden institucional a la nueva generación. Una legitimación consistente en explicaciones y justificaciones, que procuran contestar al por qué del orden socio-cultural establecido. Esta legitimación se instrumenta mediante: un sistema de objetivaciones lingüísticas, proposiciones teóricas rudimentarias (proverbios, máximas morales, leyendas, etc.), teorías como cuerpo de conocimiento diferenciado y, finalmente, universos simbólicos (construcciones últimas y omniabarcantes). Esto es, la legitimación culmina generalmente en construcciones doctrinales de naturaleza filosófica y mítico-religiosa. La vida humana diaria está llena de frustraciones, y el universo simbólico legítimamente tiene también que salvar estas situaciones. Así, por ejemplo, frente a las injusticias sociales se habla de una recompensa en otra vida, o se la considera como manifestación de un orden sobrenatural; y frente a la muerte, como caso límite de frustración, se procura dar un sentido a la misma y se la ritualiza, para procurar rehabilitar a las personas afectadas y recomponer la relaciones sociales rotas (reafirmación de la solidaridad social del grupo, de su funcionalidad y del sentido de la acción humana).

Evidentemente, la religión ha cumplido un papel capital en esta tarea de otorgar sentido a la acción humano-social: «...la religión contribuyó a promover un acuerdo sobre la naturaleza y contenido de las obligaciones sociales

27. «...el mundo animal es el de la inmanencia y la inmediatez: es que este mundo, que nos está cerrađo, lo está en la medida en que no podemos discernir en él un poder de trascenderse». G. Bataille, Teoría de la Religión, Taurus, Madrid, 1975, 27. «Nada a decir verdad, nos está más cerrado que esa vida animal de la que hemos salido. Nada es más extrafio a nuestra manera de pensar que la tierra en el seno del universo silencioso y no teniendo ni el sentido que el hombre da a las cosas, ni el sinsentido de las cosas en el momento en que quisiéramos imaginarlas sin una conciencia que las reflejase», G. BATAILlE, o.c., 24. 
proporcionando valores que sirven para canalizar las actitudes de los miembros de una sociedad, y para definirles el contenido de sus obligaciones sociales. En este sentido, la religión ayudó a crear sistemas de valores sociales, integrados y coherentes" ${ }^{28}$. El hombre necesita que el sorprendente mundo en que vive sea un «cosmos», algo, de alguna manera, dotado de sentido, y la religión ha contribuido a ello. El universo simbólico que es la religión ${ }^{29}$ proclama que ese mundo es humanamente significativo ${ }^{30}$.

Teniendo en cuenta todo lo dicho, no es de extrañar que el tema de la religión y de las convicciones morales fuera especial objeto de atención de Weber en sus estudios histórico-sociológicos de las civilizaciones.

En resumen: Weber, por un lado, tomó conciencia del proceso de racionalización que sufría el mundo moderno occidental y que se expresaba fundamentalmente en el capitalismo y la burocracia; por otro, sabía de la importancia de las ideas, creencias religiosas y convicciones morales en la configuración de la sociedad y de sus interacciones ${ }^{31}$. Por ello se preguntó: ¿qué circunstancias y factores espirituales favorecieron el alumbramiento, en Occidente, de este fenómeno tan peculiar que fue el capitalismo moderno, y que tảnto dice del sistema institucional de dicha sociedad? Y él creyó encontrar una adecuada congruencia entre el «ethos» calvinista y algunas de las fundamentales actitudes institucionalizadas en los roles seculares de nuestra sociedad. Esta tesis la desarrolló en su ensayo «La Etica protestante y el Espíritu del Capitalismo", que es también todo un ejemplo de su "sociología comprensiva». De él nos ocuparemos ahora.

28. E.K. Nottingham, Sociología de la religión, Paidós, Buenos Aires, 1964, 43.

29. "Las formas familiares de religión (...) son institucionalizaciones historicas específicas de universos simbólicos: los universos simbólicos son sistemas de significado socialmente objetivados que se refieren, por un lado, al mundo de la vida cotidiana y por el otro, señalan un mundo que se experimenta como trascendiendo dicha vida». T. LuCKMANN, La Religión Invisible, Sígueme, Salamanca, 1973, 53.

30. «Sólo cuando más allá de la pura sátisfacción o frustración cotidiana de las necesidades materiales es posịble esta reconciliación ideal que procura la participación simbólica de esos bienes ideales, el mundo social aparece como un «cosmos»; como un orden dentro del cual tiene sentido la vida humana. Así la configuraciọn de los medios y bienes de salvación aparece íntimamente ligada a la imagen ideal del mundo que frente a la pura contingencia de la vida profana establece la dimensión sagrada, a través de la cual se salva y. se legitima aquélla». C. MoyA, o.c., 124.

31. Ya sus primeras investigaciones sobre el trabajo agrario en la Alemania del Este y sobre la Bolsa de Valores, le llevaron a Weber al convencimiento de la importancia de los valores subjetivos y psicológicos en las transacciones económicas y en el comportamiento económico en general. En la primera investigación, puso de relieve cómo el factor del individualismo y la hostilidad al tipo de sujeción que implicaba el contrato anual del trabajador agrícola, le hacía partidario del régimen de asalariado, a pesar de las desventajas económicas que llo implicaba. En la segunda investigación, puso de relieve que la ética de los hombres de negocios jugaba un papel semejante. Cf. R. BendiX. «Max Weber». Amorrortu, Buenos Aires, 1970, p. 33ss. 


\section{II. «LA ETICA PROTESTANTE Y EL ESP.ÍRITU DEL CAPITALISMO»}

Weber era consciente de que había varias versiones del «capitalismo», cada una con sus peculiaridades propias. Debido a ello utilizó el método de los «tipos ideales» para resaltar las características significativas del capitalismo moderno occidental. Elaboró, pues, una construcción típica del capitalismo que se refería a un individuo histórico, y lo construyó con elementos extraídos de la realidad, aislándolos y resaltándolos ${ }^{32}$. Para Weber el capitalismo occidental se va a caracterizar por el deseo débeneficios económicos, mediante el uso de una disciplina racional en la organización del trabajo.

Es cierto que en todas las sociedades ha habido hombres deseosos de acumular dinero y riquezas pero esto, sin más, no es el fenómeno del capitalismo ${ }^{33}$. Una nota que sí es importante en el capitalismo occidental es su preocupación por comparar el resultado de sus operaciones económicas en dinero con lo que se invirtió traducido también en monedas. $Y$ es cierto que, en este sentido, también ha habido capitalismo en el mundo antiguo ${ }^{34}$. Claro que lo que predominó fue un tipo de capitalismo que Weber llama «aventurero». Un "especulador» que interviene en toda clase de aventuras financieras. Un capitalismo, en este sentido, de naturaleza irracional y especulativo ${ }^{35}$.

Pero hay en Occidente un tipo de capitalismo, que no se ha dado, claramente, en otra parte del mundo, y que se caracteriza por «la organización racional-capitalista del trabajo formalmente libre», «la separación de la economía doméstica y la industria», y por «la contabilidad racional». (Estas características si se han dado fuera de Occidente, ha sido con un carácter muy rudimentario). Este tipo de capitalismo se ha visto favorecido por el desarrollo de la técnica, el cálculo matemático, el racionalismo jurídico, una administración muy formalizada, el factor demográfico, la centralización y el desarrollo de los medios de comunicación ${ }^{36}$.

32. El «tipo puro o ideal» pretende reconstruir y resaltar los rasgos típicos de una totalidad histórica, y ello lo hace mediante una elaboración mental donde se exagera o acentúa uno o más rasgos observables de la realidad. Es, pues, una racionalización utópica y unilateral que, en último término, busca dar un significado coherente a lo que aparece confuso en nuestra experiencia. Es un concepto límite con el que se compara las situaciones de la vida real. Cf. MAX WEBER, «Economía y Sociedad», t. I, 17; R. ARON, o.c., t. II, 263; N.S. TIMASHEFF,o.c., 226; I. ZEITLIN "Ideología y teoría sociologica». Amorrotu, Buenos Aires, 1970, 136.

33. MAX WeBER, La ética protestante y el espiritu del capitalismo, Península, Barcelona, $1973,8-9$ y $52-56$.

34. «En este sentido ha habido «capitalismo» $y$ «empresas capitalistas» (incluso con relativa racionalización del cálculo del capital) en todos los países civilizados del mundo, hasta donde alcanzan nuestros conocimientos: en China, India, Babilonia, Egipto, en la Antiguledad helénica, en la Edad Media y en la Moderna» MAX WEBER, «La ética protestante...», 11.

35. Cf. MAX Weber, La ética...», 12.

36. Para un resumen más ampliado de las características del capitalismo moderno, cf. MAX WEBER, «Historia general», F.C.E. Madrid, 1974, 237-238. 
Como acabamos de decir, una nota significativa es la administración altamente formalizada. Esto es muy importante, porque sólo una división del trabajo altamente elaborada es una medida, técnicamente eficaz, en una sociedad y empresas económicas de la complejidad propia del mundo moderno. Es el racionalismo burocrático, consistente en la organización estable que posibilita la cooperación entre muchos individuos. Una cooperación donde cada uno cumple su función especial y objetivamente establecida, separada de su vida privada y del centro más profundo de su personalidad. La impersonalidad, pues, es una nota característica de la burocracia. El funcionario, como dice Aron, es un «ejecutante anónimo» ${ }^{37}$. Es cierto que el fenómeno burocrático no es patrimonio exclusivo de la época moderna. Weber señala que ya se dio en el Antiguo Egipto, en la China de la época Schi-hoang-ti, en la época del principado romano y en la Iglesia católica a partir del s. XIII. No obstante, estas burocracias antiguas tenían un matiz marcadamente patrimonial, al no darse un estatuto tan elaborado. Además solía ser dependiente del Estado.

Ahora bien, una vez definido este macrofenómeno histórico del capitalismo ${ }^{38}$, Weber se cuestiona sobre su origen, y lanza la hipótesis de que ciertas versiones del protestantismo instrumentaron motivaciones, que estimularon o favorecieron el alumbramiento y desarrollo del capitalismo moderno. Hubo una serie de informaciones y observaciones que llevaron a Weber a pensar en la posibilidad de que las concepciones religiosas pudieran influir en el tipo de actividad que el hombre ejecutaba.

En primer lugar destacados estudiosos como Montesquieu, Petty, Keats, Buckle, etc., ya habían señalado la afinidad entre el protestantismo y el desenvolvimiento del talante comercial. En segundo lugar, esta aptitud comercial por parte de los protestantes había sido reconocida en la política, cuando Federico Guillermo I consintió en que los mennonitas, pese a negarse firmemente al cumplimiento del servicio militar, realizaran operaciones comerciales al

37. Para un resumen de la concepción de la burocracia de Weber, cf. J. FreUnd, o.c., 209ss. Para ver una exposición más amplia del propio Weber, cf. cap. III, 2. ${ }^{\circ}$ punto ( La dominación legal con administración burocrática») de la primera parte de «Economía y Sociedad» t. I, 173ss.; y el cap, IX, $3 .^{\circ}$ punto («Esencia, supuestos y desarrollo de la dominación burocrática»), de la segunda parte de "Economía y sociedad», t. II, 716ss.

38. Weber coincide con Marx al afirmar que notas propias del capitalismo moderno son la búsqueda de beneficios mediante transaciones económicas en el mercado libre, la existencia de un proletariado jurídicamente libre y su carácter compulsivo-objetivo. (Para esto último, cf. «La ética...», 49). Pero Weber se separa de Marx al afirmar que la nota fundamental de la sociedad moderna es la inevitable racionalización burocrática, como algo funcionalmente necesario en una sociedad tan compleja como la industrial, más allá del régimen de propiedad que se dé en ella. Incluso piensa que el fenómeno de la burocratización se agravaría con un régimen socialista debido a su centralización planificadora. Se alumbraría lo que GiDDENS llama la «dictadura del funcionario». Weber veía con miedo el progreso de esta racionalización burocrática que amenaza con ahogar la vida espontánea y la libertad del individuo. El hombre aprisionado por la «jaula de hierro" de la división especializada del trabajo. 
Estẹ de Prusia. En tercer lugar, constató, en términos generales, que en Alemania, los protestantes de ciertas iglesias poseían las fortunas más considerables y ocupaban los puestos más significativos de la vida económica. En cuarto lugar, hubo informaciones, que fueron decisivas en orden a que Weber profundizara en el estudio verificador de su hipótesis: se daba el hecho de que los protestantes (en Baden, Baviera, Hungría...) eran más proclives a cursar estudios técnicos y a emprender actividades económico-capitalistas, mientras que los católicos lo eran a cursar estudios humanísticos. Incluso en el medio obrero, los protestantes dominaban en los puestos que implicaban capacidades profesionales avanzadas desde el punto de vista técnico, mientras que los católicos ejercían más frecuentemente las actividades artesanales ${ }^{39}$. Por último, Weber observa el hecho significativo de que los católicos a pesar de soportar, en Alemania, una legislación opresora desde 1870, no adoptaron el tipo de comportamiento frecuente en estos casos: las minorías excluidas de la vida social y política, suelen compensar esta marginación volcándose en la vida económica ${ }^{40}$. Por contraposición, han sido los protestantes los que han mostrado una preferencia por el racionalismo económico. Por todo ello, Weber piensa que, "La razón de tan distinta conducta ha de buscarse, pues, en una determinada característica personal permanente y no sólo en una cierta situación histórico-política de cada confesión.

La cuestión sería, ante todo, investigar qué elementos de las características confesionales son o fueron los que obraron $y$, en parte, siguen obrando en la dirección descrita» ${ }^{41}$.

Y así, Weber se dedicó, en la obra que comentamos, a verificar su hipótesis, haciendo ver el conformismo existente entre el espíritu de la ética protestante y el del capitalismo; es decir, a poner de manifiesto una relación comprensiva entre el espíritu de cierta religiosidad protestante y una serie de actitudes implicadas en la praxis capitalista ${ }^{42}$.

Para poner de relieve el espíritu del capitalismo, como conjunto de actitudes respecto de la adquisición del dinero y del trabajo, Weber echa mano de los textos de Benjamín Franklin ${ }^{43}$. Dichos escritos nos describen el ideal de la

39. Estas informaciones se las aporto Weber a un alumno suyo, al que encargó un trabajo sobre las relaciones entre la afiliación religiosa y los gustos educacionales en el estado de Baden. Cf.M. OfFEnBacher, Konfessions und soziale Schichtung, Tubingen y Leipzig, 1901 (vol. IV, fac. 5 de los Cuadernos de Economía de la Universidad de Baden). Cf. también Max WeBER, «La ética...", 30-31.

40. Weber cita el caso de los polacos en Rusia, los hugonotes en la Francia de Luis XIV, los no conformistas y los cuáqueros en Inglaterra, y por supuesto el caso de los judíos.

41. Max Weber, o.c., t. I., La ética..., 32-33.

42. Para llevar a cabo esta tarea Weber investigó el protestantismo holandés del siglo XVI y XVII, sobre las empresas capitalistas de hugonotes y católicos en la Francia del s. XVI y XVII, y sobre el puritanismo ingles y su proyección en Nueva Inglaterra.

43. B. Franklim, Advertencias necesarias a los que quieren ser ricos (1736), y Consejos a un joven comerciante (1748). Para leer algunos párrafos muy significativos, cf. Max WEBER, o.c., La ética..., 42-43. 
laboriosidad, la firmeza y constancia en el duro trabajo, la puntualidad, la honestidad y prontitud en el pago de las deudas, la frugalidad y la preocupación por el ahorro. Además el trabajo como actividad adquisitiva y la ganancia como ahorro, aparecen no como medios sino como fines en sí éticamente sancionados ${ }^{44}$. La ganancia legal es el resultado y la expresión de la virtud.

Además Weber no cree que el espíritu y la ética capitalistas que reflejan los escritos de Franklin puedan ser meros reflejos ideológicos de factores materiales, pues en Massachussetts, patria de Benjamín, no había todavía una sólida infraestructura capitalista. El origen habrá, pues, que buscarlo en las doctrinas protestantes. (Aunque Franklin era un deísta aconfesional, su padre fue un severo calvinista...).

De este modo, Weber se asoma al mundo de la Reforma, y observa que ya con Lutero surge un nuevo concepto de gran importancia para lo que él busca: el de «BERUF» (profesión). Con este término se quiere dar un significado religioso y moral a las tareas cotidianas. La vocación así entendida, es una tarea obligatoria, moralmente hablando, y querida por Dios. Es la única manera de vivir aprobada a los ojos de Dios ${ }^{45}$.

Ahora bien, como indica Weber, Lutero, a pesar de presentar esta valoración ética profesional, no es el impulsador del ethos capitalista, ya que su actitud frente al préstamo a interés, la usura y la acumulación de riquezas es propia de una mentalidad que no se diferencia de la del catolicismo tradicional ${ }^{46}$. Un tradicionalismo que se afianza en Lutero tras las revueltas campesinas de carácter comunitario, al defender el orden social vigente como una determinación de la voluntad divina. Cada cual debe aceptar el lugar que le ha tocado en la vida ${ }^{47}$. Por tanto, lo original de la Reforma de Lutero fue, en el orden ético

44. «...el summum bonum de esta 'ética' consiste en que la adquisición incesante de más y más dinero, evitando cuidadosamente todo goce inmoderado, es algo tan totalmente exento de todo punto de vista utilitario o eudemonista, tan puramente imaginado como fin en sí, que aparece en todo caso como algo absolutamente trascendente e incluso irracional frente a la «felicidad» o utilidad del individuo en particular», Max WeBer, La ética..., 48.

45. Cf. Max Weber, La ética..., 83-90.

46. Cf. Max Weber, La ética..., 75-76.

47. Cf. Max Weber, La ética..., 98-99. También TroeltsCh afirma que no se debe descuidar «que la idea protestante del oficio en su sentido luterano, guardaba estrecha conexión con la sociedad conservadora estamentalmente articulada, que mantiene a cada uno en su estado, y sólo pide de la superioridad la subsistencia suficiente, mientras fomenta, por otro lado, la resignación ante las injusticias del mundo.

Se trata de la misma actitud tradicionalista en la vida prescrita por el catolicismo (...) Con todo esto concuerda del todo el ideal económico de Lutero, orientado desde el punto de vista agrario y artesanal, y que mantiene la prohibición económica del cobro de intereses. Ataca el régimen monetario y crediticio y, especialmente, el comercio al por mayor, con tanta pasión como cualquier autor medieval (...) jamás la piedad luterana ha albergado un impulso para el desarrollo económico fuerte y no lo ha desarrollado tampoco en la estrechez de las circunstancias alemanas», E. TroelsTCH, «El protestantismo y el mundo moderno», F.C.E., México, 1967, 70 . 71. 
la desaparición de los deberes ascéticos específicos del monaquismo medieval (no a la distinción católica de las normas evangélicas ante "praecepta» y «consilia»), la conformidad con la autoridad y con el orden social y la acentuación del matiz ético-religioso otorgado al trabajo mundano entendido como «profesión». Pero esto, debido a los otros aspectos señalados, no fue suficiente para el nacimiento del espíritu moderno. En cambio, Weber, ve al calvinismo como un movimiento religioso que favoreció la maduración y el desarrollo del espíritu capitalista ${ }^{48}$; sobre todo el calvinismo del s. XVI, XVII y XVIII. Y ello, aunque este efecto histórico no fuera premeditado y deseado conscientemente por el propio Calvino ${ }^{49}$. Pero Weber pone de relieve, por medio de su método comprensivo, cómo el calvinismo presenta una actitud en relación a la actividad económica que se adapta significativamente a la que implica el espíritu del capitalismo.

Para exponer la concepción calvinista, nuestro autor comienza por citar las proposiciones más significativas de la Confesión de Westminster de 1647 en la que comulgan las confesiones independientes y bautizantes ${ }^{50}$. El calvinismo, como se ve en estos textos, postula la existencia de un Dios absolutamente trascendente e inaprensible para el hombre, creador de un mundo para su propia gloria, que en su omnipotencia inescrutable, ha predestinado a unos hombres a la salvación y a otros a la condenación, y esto sin que nuestras obras tengan en ello incidencia alguna. Las cosas terrestres son ya pecado y muerte, pero el hombre (salvado o condenado para gloria de Dios) debe trabajar para crear el reino de Dios en la tierra.

Ante todo, cabe resaltar la patética soledad en que se encuentra el hombre que asume esta concepción religiosa, que frente al enigma de su destino no puede encontrar ayuda ni en el prójimo, ni en los sacramentos, ni en la Iglesia, ni en el mismo Dios ${ }^{51}$. Se elimina, pues, la posibilidad del misticismo

48. Weber para la exposición del espíritu del calvinismo y de la ética reformada tuvo en cuenta los escritos y predicas de autores como Richard Baxter, Spener, Jogn Bunyan, Charnock, Bayley, etc., etc.

49. «...no pretendemos afirmar que en los fundadores o representantes de estas confesiones (calvinismo) se encuentre un despertar de lo que llamamos «espíritu del capitalismo», como finalidad de su trabajo y actividades vitales. Ninguno de ellos consideraba la aspiración a los bienes terrenales como un valor ético, como un fin en sí (...) La salvación de las almas y sólo esto erà el eje de su vida y su acción (...) Por eso los efectos de la Reforma en el orden de la civilización (...) eran consecuencias imprevistas y espontáneas del trabajo de los reformadores, desviadas y aun directamente contrarias a lo que éstos pensaban y se proponian», Max WEBER, La ética..., 105-106.

50. Cf. Max Weber, La ética..., 118-119.

51. Con relación a la felicidad eterna... «Nadie podía ayudarle; no el predicador, porque sólo el elegido era capaz de comprender espiritualmente la palabra de Dios; no los sacramentos, porque éstos son, es verdad, medios prescritos por Dios para aumento de su gloria (por lo que han de practicarse absolutamente), pero no son medios para alcanzar la gracia, sino (subjetivamente) simples externa subsidia de la fe. Tampoco la Iglesia, pues (...) a la Iglesia (externa) pertenecen también los excomulgados, quienes deben ser sometidos a su disciplina no para alcanzar de ese 
(al no ser posible la comunicación, en este sentido, entre Dios y el hombre), el rito como superstición y toda forma de idolatría, donde se incluyen los elementos sensibles y sentimentales de la vida religiosa subjetiva. Es la coronación de ese proceso de "desencantamiento" del mundo, que se inició con el profetismo judío ${ }^{52}$, y que luego se combinó con el pensamiento griego negador de los medios mágicos para la salvación. Cabe también indicar que el calvinismo «es una de las raíces del individualismo desilusionado y pesimista todavía influyente en el "carácter popular» y las instituciones de los pueblos de pasado puritano» ${ }^{53}$. En la literatura británica puritana se defiende incluso la idea de desconfiar de los amigos y sólo confiar en Dios (Baxter, Bailey) ${ }^{54}$.

También hay que reconocer que la actitud negativa frente a la idolatría, la magia y el misticismo, favorecía el reconocimiento del orden natural, y abría paso al desarrollo de las ciencias. El mundo es manifestación y creación de Dios, por esta razón, era una vía para conocer, de algún modo, a Dios (aunque se siga postulando la total trascendencia de su realidad íntima) ${ }^{\text {ss. }}$.

Según la tesis de la predestinación, hay que aceptar, pues, el hecho de la inescrutable elección de Dios y debemos confiar en Cristo, si tenemos auténtica fe. Es decir, se impone el deber de considerarse elegido, y toda duda debe ser rechazada como tentación. La debilidad en la fe es seffal de insuficiencia de gracia. Weber nos recuerda la figura del «santo seguro de sí mismo» que se daba entre los mercaderes puritanos de la época heroica del capitalismo.

Pero lógicamente y a pesar de todo, para el hombre corriente de la calle, la cuestión de la "certitudo salutis» debió convertirse en una temática acuciante, y la incertidumbre debio convertirse en una tortura psíquica insoportable. Frente a ello, el criterio rigurosamente «ortodoxo», el autotestimonio de la fe que se mantiene y perdura, no era suficiente. Esta problemática se impuso,

modo la eterna felicidad (...), sino porque también ellos deben ser forzados, ad gloriam Dei, a observar sus preceptos. Por último, tampoco Dios podía prestar aquella ayuda, pues el mismo Cristo sólo murió por los elegidos», Max WeBER, La ética..., 123-124.

52. H. Cox en su libro La Ciudad secular, Península, Barcelona, 1968, 43-59, seffala cómo la primera ráz de la secularización está en la misma Biblia, por el impacto de su fe en la historia humana: la noción bíbliça de «creación» implica el desencantamiento de la naturaleza; el «Exodo» la desacralización de la política; y el pacto del Sinál la desconsagración de los valores.

53. Max Weber, La ética..., 125-126.

54. «Los conciliábulos y sectas ascéticas constituyeron una de las bases históricas más importantes del «individualismo» moderno. Su radical ruptura con los lazos patriarcales y autoritarios, así como su modo de interpretar la afirmación de que se debe mayor obediencia a Dios que al hombre fue particularmente importante Max WEBER, «Ensayos de Sociología contemporánea», Martínez Roca, S.A., Barcelona, 1972, 393.

55. «El punto de vista decisivo del ascetismo protestante (...) era que así como se reconoce al cristiano en los frutos de su ie, así también el conocimiento de Dios y de sus designios sólo puede extraerse del conocimiento de sus obras. Por eso, la disciplina preferida de todo el cristianismo puritano, bautizante y pietista era la fisica y aquellas otras disciplinas matemáticonaturales que operaban con un método análogo», Max WEBER, La ética..., nota 146, 182. 
sobre todo, en la cura de almas. Y de esta situación salieron dos consejos prácticos: uno el deber de esforzarse por considerarse uno elegido. $Y$ «En segundo lugar como medio principalísimo de conseguir dicha seguridad en sí mismo, se inculcó la necesidad de recurrir al trabajo profesional incesante, único modo de ahuyentar la duda religiosa y de obtener la seguridad del propio estado de gracia» ${ }^{56}$. Ésta era, en verdad, la única salida que le quedaba a la teología calvinista en sus planteamientos prácticos: el ascetismo, como signo de gracia. La declaración de Westminster defendía la idea de que el mundo estaba destinado para honrar a Dios, lo mismo que el cristiano realizando las tareas y cumpliendo los preceptos que le correspondían. Y dentro de este contexto, «el trabajo social del calvinista en el mundo se hace únicamente in majorem Dei gloriam. Y exactamente lo mismo ocurre con la ética profesional, que está al servicio de la vida terrenal de la colectividad" ${ }^{57}$. El trabajo racional en el mundo aparece, pues, como un medio para dar gloria a Dios. Por otro lado, debido a la trascendencia divina, su comunión con los elegidos «sólo podía realizarse y conocerse cuando Dios «actuaba» (operatur) en ellos, y éstos se daban cuenta de ello; es decir cuando su acción provenía de la fe actuada en ellos por la divina gracia y, a su vez, esa fe se legitimaba como actuada por Dios por la calidad de aquel obrar" ${ }^{58}$. Y como los sentimientos nos pueden engañar, «la fe necesita comprobarse en sus efectos subjetivos, para servir de base segura a la certitudo salutis: ha de ser una fides efficax» ${ }^{59}$. Por tanto, la conducta que aumenta la gloria de Dios es la que cumple con los mandamientos directamente revelados por Dios y la que desarrollá la ley de la naturaleza. Y las buenas obras y el éxito en el trabajo serán, no medios para alcanzar la salvación, pero sí signos de elección. Teniendo en cuenta todo esto, se comprende que los efectos del calvinismo en el s. XVII fuesen una vida metódica y sistemática ${ }^{60}$. Como indica Weber, el fruto de esta metodización de la conducta ética fue una cristianización de toda la existencia. Se alumbra, pues, un riguroso ascetismo intramundano de corte racional, que coloca en un lugar destacado al trabajo profesional como vocación. La antítesis de este espíritu será el goce espontáneo y despreocupado de la vida ${ }^{61}$.

56. Max Weber, La ética..., 138. Esta idea se repite mucho en el «Christian Directory de Baxter. Confert también: Max Weber, o.c., nota 67, p. 145-146.

57. Max WeBER, La ética..., 131.

58. Max WEBER, La ética..., 141.

59. Max WEBER, La ética..., 142.

60. «El Dios del calvinista no exigía a sus fieles la realización de tales o cuales «buenas obras», sino una santidad en el obrar elevada a sistema (...). La vida del «santo» se encaminaba a una finalidad única: la bienaventuranza; pero justamente por eso, el decurso de esa vida suya fue absolutamente racionalizado y dominado por la idea exclusiva de aumentar la gloria de Dios; jamás se ha tomado más en serio este principio de omnia in majorem Dei gloriam». Max WEBER, La ética..., 149-150.

61. Cf. Max Weber, La ética..., nota 80, p. 152; Mas Weber Ensayos de sociología contemporánea, Martínez Roca S.A., Barcelona, 1972, 356; E. Troeltsch, o.c., 47 y 49. 
El cambio de mentalidad que esto conlleva es profundo: el trabajo ya no aparece como la maldición bíblica del Génesis, ni como una mera táctica para combatir la sensualidad de la carne, sino que ahora aparece como un mandato de Dios que debía de cumplir el que quisiese contruir el Reino de Dios en la tierra. La motivación negativa del trabajo era sustituida por otra positiva: el trabajo bien hecho y el éxito económico implicaban cumplir la voluntad de Dios y eran signo de su gracia.

Esta ética y este ascetismo intramundano se prolongaron, con unos u otros matices, en el puritanismo, el pietismo y las sectas anabaptistas, teniendo una gran trascendencia para el desarrollo del capitalismo moderno ${ }^{62}$. Podemos decir, pues, que el ascetismo protestante eliminó «los frenos que la ética tradicional ponía a la aspiración a la riqueza, rompía las cadenas del afán del lucro desde el momento que no sólo lo legalizaba, sino que lo consideraba como precepto divino" ${ }^{63}$. Este lucro, desde luego, entendido como fruto del trabajo ascético y con una finalidad de utilidad para la comunidad, no para el uso irracional (lujo desmedido y sensualidad desenfrenada). Por ello nos dirá Weber: «La valoración ética del trabajo incesante, continuado y sistemático en la profesión, como medio ascétido superior y como comprobación absolutamente segura y visible de regeneración y de autenticidad, tenía que constituir la más poderosa palanca de expansión de la concepción de la vida que hemos llamado «espíritu del capitalismo». Si a la estrangulación del consumo juntamos la estrangulación del espíritu de lucro de todas sus trabas, el resultado inevitable será la formación de un capital como consecuencia de esta coacción ascética para el ahorro" ${ }^{64}$. Se da, pues, como dice Aron, un ajustamiento entre ciertas exigencias de la lógica teológica y las de la lógica capitalista.

Tras todo lo considerado hasta aquí, se comprende que «La ética protestante y el espíritu del Capitalismo» es una obra que es ejemplo del «método

62. Weber, en su obra, hace referencia al pietismo holandés y de la Baja Renania como una corriente que se desgajó del calvinismo y que implicó una exacerbación del ascetismo reformado; al pietismo alemán (Spener, Franke y Zinzendorff) que nació en el seno del luteranismo germano y que, aunque se apartó de la vida de la predestinación y fomentó un sentimentalismo religioso, también defendio la idea de una ascetización de la conducta; el metodismo (otra versión del pietismo continental), sobre todo el americano (J. Wesley), con su metodización sistemática de la conducta para alcanzar la certitudo salutis junto con el acto sentimental de la conversión. Pero, sobre todo, junto al calvinismo, Weber sefiala como segundo gran representante del ascetismo a las sectas bautizantes (Suiza, Norte de Alemania), y las sectas baptistas, mennonistas y los cuáqueros (continuadores de la tradición bautizante con George Fox), todas ellas nacidas del calvinismo en. los siglos XVI y XVII. Por último, Weber alude a Richard Baxter representante del puritanismo ingles (movimiento nacido dentro del calvinismo). Quizás haya sido Baxter el autor que haya elaborado la fundamentación más consecuente - según Weber - de la idea de profesión. Según nuestro autor, su Christian Directory es el mejor compendio de moral puritana, orientado hacia las necesidades prácticas de la cura de almas.

63. Max WeBer, La ética..., 242.

64. Max Weber, La ética..., 244-245. 
comprensivo» de Weber. Para llegar a determinar el origen del capitalismo moderno era necesario «comprender lo que hacían aquellos hombres. Para conseguirlo, Weber estudió la concepción del mundo que defendían, a través de la cual podía descubrir el sentido de sus actos y de sus vidas. Y esto último lo llevó a la religión, particularmente a la ética calvinista, pues, en sus concepciones, creyó ver rasgos de esta última secularizados ${ }^{65}$. Con todo ello, Weber puso de manifiesto un problema sociológico de enorme importancia: la influencia de las ideas en las organizaciones sociales.

\section{MAX WEBER SOCIÓLOGO DE LA RELIGIÓN}

Los posteriores estudios de Weber sobre la posible incidencia de las creencias religiosas en la vida y la acción sociales fueron mucho más ambiciosos ${ }^{66}$, aunque, en último término, sirvieron para valídar la tesis defendida en «La ética protestante y el Espíritu del Capitalismo».

Weber pretendió analizar en qué medida las características religiosas de otras civilizaciones fueron favorables o no, al desarrollo de un tipo de capitalismo occidental en aquellas sociedades. Con este fin, nuestro autor llegó a desarrollar una sociología comparada de las grandes religiones superiores, en la que busca averiguar si existe alguna concepción religiosa que llegue a plasmarse (con la conjugación de otros factores y circunstancias) en un comportamiento capitalista moderno. Si no encontrara dicha concepción y el resto de las condiciones fuesen relativamente semejantes ${ }^{67}$, entonces sería lógico pensar que en el nacimiento y desarrollo de las características socio-económicas de Occidente jugó un papel importante la concepción religiosa del protestantismo. Es decir, Weber utiliza lo que se puede llamar el «método de la ausencia” ${ }^{68}$. Destaquemos algunas de las conclusiones más importantes de Weber, aunque no sea esta temática la central de nuestro trabajo.

65. «La enajenación por el trabajo y la ganancia, que constituye el ascetismo indeliberado e inconsciente del hombre moderno, es una hija del ascetismo intramundano del trabajo y del oficio, consciente y religiosamente fundado", E. TroeltSCH, o.c., 73.

66. El resultado de estas investigaciones están recopiladas en «Gesammelte Aufsăze zur Religionssoziologie» (J.C.B. Mohr, Tubinga, 1920). Una síntesis bien elaborada se encuentra en la monografía de R. Bendix, M. Weber. Amorrortu, México, B. Aires, 1970 pp. 93-270.

67. Weber tuvo en cuenta que una ética religiosa es un entidad concreta, y por tanto susceptible de estar influida por diversos aspectos de la realidad socio-cultural en cuestión. Por ello procuró ser sumamante minucioso y cuidadoso en sus investigaciones y no hacer afirmaciones - como veremos en nuestra conclusion - unilaterales. Por otro lado, las dificultades y limitaciones de estudios tan amplios y complejos son enormes, por ello, Weber, procuró hacer afirmaciones en términos de probabilidad.

68. En muchos casos, «sólo queda la posibilidad de comparar el mayor número posible de hechos de la vida histórica o cotidiana que, semejantes entre sí, sólo difieran en un punto decisivo: el «motivo» u «ocasión», que precisamente por su importancia práctica tratamos de investigar». Cf. Max Weber, Economía y sociedad, F.C.E., México, 1969, T.I., 10. 
En China, a pesar de sus notables reservas de metales y su densidad de población, no se dio el fenómeno del capitalismo moderno ${ }^{69}$. Las ciudades no gozaban de una conveniente autonomía política, ni de un poder militar propio; también se notaba la ausencia o escaso desarrollo de una asociación política de comerciantes y de corporaciones profesionales. Además «en China el grupo consanguíneo era tan poderoso que la verdadera enajenación de la tierra era imposible. La tierra no se vendía de manera incondicional o permanente; por el contrario, el grupo consanguíneo siempre conservaba el derecho a comprarla" ${ }^{70}$. Es cierto que se daba el fenómeno burocrático, pero con unas características particulares que le hacian a Weber llamarlo «burocracia patrimonial». Era una burocracia centralizada (de la que dependian las ciudades) administrada por las «mandarines» del Emperador; hombres de formación literaria, pero carentes de una formación especializada y técnica. Por esta razón, la administración racional real, dependía de unos subordinados, que no estaban sujetos a la disciplina burocrática. Estos subordinados dependían del mandarín tanto en su nombramiento como en sus remuneraciones, y muchas veces eran representantes de los intereses de la localidad. Todo ello, como es natural, no favorecía la gestión de cara a una racionalización general, no mediatizada por los intereses locales que implicaban generalmente, un irracionalismo.

Pero lo más importante es que, ni el confucionismo, ni el taoísmo favorecieron un ascetismo racional intramundano abierto al progreso. Para el taoísmo, el poder impersonal del "Cielo», se expresaba en el orden de la naturaleza y la tradición. Por tanto, los fines de la vida y su estilo estaban dados, y este equilibrio no tenía por qué alterarse. Además la magia y el animismo no favorecieron el desarrollo de la técnica científica. En el confucionismo también encontramos este reconocimiento y aceptación de un orden de la realidad regulado por el "Cielo». La sociedad es un microcosmos de ese orden cósmico. La piedad filial confuciana, que se expresaba en una serie de ritos, no era tampoco favorecedora de la racionalización ética y del cambio. Era una virtud eminentemente tradicionalista y estática, como todo el ideal del caballero confuciano $^{71}$. Faltó, por tanto, un código ético semejante al del calvinismo, fomentador de un ascetismo intramundano, del espíritu de progreso y de un desarrollo económico.

69. «Muy pronto China tuvo una paz permanente en una amplia área. Tuvo relativamente pocas restricciones a la movilidad interna y al comercio. Tuvo un grado desusado de igualdad de oportunidades y de libertad en la elección de las ocupaciones. Estuvo prácticamente libre de restricciones al desarrollo económico, tales como la prohibición católica a la usura (...). Si como se piensa a menudo, sólo la falta de circunstancias restrictivas podía determinar un desarrollo capitalista habría, sin duda, sucedido en China mucho antes de la era moderna». Talcott PARSONS, La estructura de la acción social, Guadarrama, Madrid, 1968, t. II, 674.

70. I. ZeitLin, o.c., 160.

71. Cf. Betty, R. Scharf, El estudio sociológico de la religión, Seix Barral, Barcelona 1974, 217. 
Como indica Zeitlin, «también en la India veia Weber muchas condiciones culturales y sociales que, al parecer, podian haber dado origen al capitalismo racional moderno. Se había racionalizado el arte de la guerra, las finanzas y la política, por ejemplo, y aun ésta última en términos totalmente «maquiavélicos». En uno u otro momento, habían aparecido muchas de las formas capitalistas de viejo cuño; acreedores y contratistas estatales, recolectores de impuestos, etcétera (...). Además lo que Weber llamaba racionalidad predominaba en numeroso ordenes de la vida cultural india: el sistema numérico racional, la aritmética, el álgebra, la ciencia racional y, en general, una racional coherencia en muchas esferas, junto con un alto grado de tolerancia hacia las doctrinas filosóficas y religiosas. Las formas jurídicas prevalecientes parecían compatibles con un desarrollo capitalista; existía un estrato autónomo de mercaderes; los oficios y especialización profesional habían alcanzado considerable desarrollo; y finalmente, el alto grado de ansia adquisitiva y elevada valoración de la riqueza constituían aspectos notables de la vida social india» ${ }^{72}$.

No obstante la compleja espiritualidad religiosa de la India impidió, a juicio de Weber, el desarrollo del capitalismo moderno y de su espíritu. En primer lugar, el sistema de castas. «Está muy claro que el sistema de castas, con su extremo de inmovilidad tanto vertical como territorial y su jerarquía, virtualmente sancionada, de ocupaciones tradicionalmente estereotipadas, constituye una barrera casi insuperable a tal desarrollo; y sin duda a un desarrollo espontáneo a partir de fuentes indígenes" ${ }^{73}$. El alcance de este sistema de estratificación no se puede valorar sin tener en cuenta las creencias religiosas de la India y, sobre todo, la doctrina de la transmigración de las almas. Según esta última, el lugar que ocupamos en la jerarquía de castas viene determinado por la devoción religiosa y el grado con que respetamos las exigencias de castas en la vida anterior. Las creencias religiosas, pues, favorecían el mantenimiento del orden existente ${ }^{74}$.

En segundo lugar, en la espiritualidad de la India, en términos generales, late un pesimismo metafísico que se traduce en una desvalorización de la subjetividad y del mundo fenoménico y en un panteísmo nihilista. Su resultado era una huida contemplativa del mundo, que desde luego no es conjugable con una forma de vida metódica e innovadora, que debilitara el tradicionalísmo. Weber llega a la conclusión de que cuando una religión presenta valores religiosos y medios de redención de carácter contemplativo y orgiástico-extásico,

72. I. Zeituin, O.c., 164.

73. T. PARSONS, o.c., t. II, 687.

74. «El interés religioso del individuo no podía nunca consistir en la perturbación del sistema, sino sólo en la mejora de sus posibilidades de una mejor encarnación dentro del sistema (...). Realmente, apenas si cabía diseffar una sanción del tradicionalismo más completamente estanca y eficaz». T. PARSONS, o.c., t. II, 690. 
la acción mundano-económica es considerada como algo inferior y es fácil la proclividad hacia una antropología mágica ${ }^{75}$.

Junto a la contemplación también es cierto que aparece un ascetismo en la India, pero que implica una huida del mundo: "Las actividades ordinarias de este mundo, la vida familiar, económica y política, son deberes que han de cumplirse, pero que no constituyen el aspecto más importante de la vida ${ }^{76}$. Los más grandes maestros enseñan que el mundo de los fenómenos es un mundo ilusorio, y demuestran que, por diversos métodos de autodisciplina física, meditaciones y rezos, los hombres pueden llegar a percibir una realidad más allá de la transitoriedad de los objetos materiales y las relaciones sociales. Más allá de los deberes sociales y rituales reside la posibilidad de consagrarse a este tipo de experiencias" ${ }^{7}$. Hay por tanto, unos rasgos comunes a los desarrollos religiosos de la India y de la China, más allá de sus diferencias: «La racionalización del pensamiento religioso, en ambos casos, marchó en la dirección inmanente, impersonal y panteísta, partiendo de la concepción de un orden impersonal de fuerzas rituales, tao y ritos. Conectado a este hecho está el de que en ninguno de los dos desarrollos apareció un movimiento de profecía ética, fijando criterios éticos opuestos al orden tradicional» ${ }^{78}$.

Por último, digamos que Weber estaba convencido de la enorme importancia del judaísmo en los comienzos de la civilización occidental, y ello porque el judaísmo presenta una ética religiosa racional, que es enemiga de la magia y de los caminos irracionales de la salvación. No obstante esta ética tampoco dio como fruto un capitalismo racional moderno. Weber cree encontrar la razón en: $1 .^{\circ}$ ) el dualismo ético hebraico, defensor de una moral con relación al extranjero que permitía ciertos comportamientos, prohibidos, en contraposición, por la moral vigente en relación con los hermanos judíos; $2 .^{\circ}$ ) la ausencia de actitudes y valores ascéticos, que favoreció un tipo de capitalismo que ya hemos denominado «aventurero».

Por lo tanto, el lugar donde el proceso de desencantamiento del mundo y de racionalización intramundana ha sido llevado a extremos notables, ha sido Occidente; la estructura económico-social del capitalismo moderno da testimonio de ello. $\mathrm{Y}$ ese proceso parece que fue favorecido $\mathrm{y}$ acelerado por el ethos del protestantismo.

75. Cf. Max WeBER, Ensayos de sociología contemporánea, Martínez Roca, s.a., Barcelona $1972,353-354$ y 398.

76. Esto engendra en la espiritualidad de la India una ambigutedad y tensión que muy bien explica A. Schweitzer en su obra El pensamiento de la India, F.C.E., Buenos Aires 1958.

77. Betty R. SCHARF, o.c., 216.

78. T. PARSONS, o.c., t. II, 706. 


\section{REFLEXIÓN CRÍTICA}

Según Timasheff, «en los años de juventud Weber quiso poner a prueba la afirmación básica del marxismo, según el cual todos los fenómenos culturales, incluso la religión, están fundamentalmente determinados por la evolución de las fuerzas económicas. Para Marx la Reforma protestante fue un subproducto del nacimiento del capitalismo. Weber decidió someter a prueba esa hipótesis, y llegó a una conclusión diferente (...) El capitalismo moderno o maduro (...) nació no simplemente por una necesidad económica interna, sino como si fuera impulsado por otra fuerza naciente: la ética religiosa del protestantismo, y en especial del calvinismo (...).

Según Weber, esas máximas de conducta religiosa y secular estaban tan de acuerdo entre sí, que el nacimiento de la orientación ética protestante puede considerarse como condición necesaria, aunque no suficiente, del nacimiento del capitalismo moderno" ${ }^{79}$. Como vemos en estos párrafos escogidos de Timasheff, éste, en su interpretación de la obra de Weber que estudiamos, se acerca mucho a una interpretación causalista que cuestiona al materialismo histórico.

En cambio, A. Giddens nos indica que resultaría erróneo considerar esta obra «como un ataque frontal al materialismo histórico. Más bien, la línea de evolución del razonamiento de Weber, tanto en relación con la estructura social de Alemania, como el en plano intelectual más general, le llevó a adoptar un punto de vista que se cruzaba con las concepciones típicas encarnadas en el marxismo" ${ }^{80}$. No obstante, reconoce que la obra de Weber cuestiona implícitamente algunos planteamientos del materialismo histórico. Así nos dice que Weber «se mostró de acuerdo con determinados elementos del análisis marxista convencional sobre la ideología religiosa, pero rechazó de todas formas el materialismo histórico "unilateral» ${ }^{71}$ que no concedía ninguna influencia positiva al contenido simbólico de las formas específicas del sistema de creencias religiosas» ${ }^{82}$. Es decir, está claro que Weber se enfrentó con los análisis marxistas acerca de la Ideología y la Infraestructura, al tratar la cuestión del papel de las ideas en el desarrollo histórico. Y Giddens matiza: «El propio Weber rechazó con dureza las afirmaciones del materialismo histórico a este respecto; la concepción de que los sistemas ideológicos pueden en algún sentido reducirse «en último extremo» a los factores económicos está rotundamen-

79. N.S. TIMASHEFF, o.c., 217-218.

80. A. GidDENS, o.c., 47.

81. Otra cuestión será si Marx fue defensor de ese «marxismo vulgar y unilateral». Parece desde luego que, aunque en Marx y en Engels hay textos para todos los gustos, no serían partidarios de esa versión simplificada que es un «economicismo excesivo». Aunque el marxismo da una mayor valencia a la «infraestructura», defiende una relación de «sobredeterminacion» o dialéctica entre ésta y la superestructura. Cf. J.M. Rodriguez PANiagua, Marx y el problema de la ideología, Tecnos, Madrid, 1972.

82. A. GidDENS, o.c., 48. 
te periclitada; la verdad es que no existe ninguna línea unilateral de relación entre los factores "materiales» y los «ideales»" ${ }^{83}$.

Freund por su parte, afirma que «La Ética protestante y el espíritu del Capitalismo», de algún modo, "...es una réplica al dogmatismo escolástico del marxismo, que ha reducido metafísicamente todos los acontecimientos de la civilización a una sola causa: el substrato económico que constituye en último análisis la explicación última. Semejante prejuicio es incompatible con la investigación científica que no puede imponer por adelantado el resultado al que debe llegar el análisis» ${ }^{84}$.

Ahora bien, frente a esta interpretación de contraste y crítica al materialismo histórico, la valoración de I. Zeitlin es muy opuesta. (Tanto, lo veremos, que en último término, intentará invalidar la tesis de Weber). Según Zeitlin, la obra, situada en el contexto de su sociología de la religión, no pretendió refutar el método marxista, aunque introdujera algunas modificaciones. Y nos recuerda: "Aunque a veces habla de correlación y otras de influencia causal, afirma con mucha claridad que trata deliberadamente de «sólo un aspecto de la cadena causal», a saber, la influencia de los valores religiosos sobre la conducta económica» ${ }^{85}$. Ciertamente en esta observación tiene razón Zeitlin. En la misma línea nos lo advierte Aron: «Con respecto al materialismo histórico, el pensamiento de Weber no es una inversión de positivo o negativo. Nada sería más falso que suponer que Max Weber sostuvo una tesis exactamente contraria a la de Marx, y que explicó la economía por la religión en lugar de explicar la religión por la economía. No se propone invertir la doctrina del materialismo histórico para reemplazar la causalidad de las fuerzas económicas por una causalidad de las fuerzas religiosas..." ${ }^{86}$. Y ello, no sólo, porque una vez desarrollado el régimen capitalista, es el medio socioeconómico el que, en gran medida, determina las formas de la conducta, (y si no ahí tenemos el desarrollo secularizado del capitalismo como prueba), sino porque desde el punto de vista epistemológico y metodológico, Weber no era partidario de la unidirección causal o causalidad exclusiva. Weber sabía que si la conducta económica del hombre podía estar influida por sus creencias, también el medio económico y otra serie de factores podian incidir en el mundo de las ideas. Es decir, Weber no pretendió nunca sustituir una interpretación causal «materialista» por otra exclusivamente «espiritualista». Nos lo recuerda explícitamente al final de su ensayo: «Hemos procurado poner de relieve los motivos fundamentales del hecho y el modo de su actuación en sólo un punto, el más importante ciertamente. Por lo mismo ahora debería investigarse la manera cómò el ascetismo protestante fue influenciado a su vez en su de-

83. A. GIDDENS, o.c., 50.

84. J. FREUND, O.c., 182.

85. I. ZeItLIN, O.c., 139.

86. R. Aron, o.c., 291. Cf. Max Weber, La ética..., 196 y 107. 
senvolvimiento y características fundamentales por la totalidad de las condiciones culturales y sociales, singularmente económicas, en cuyo seno nació. Pues reconociendo que, en general, el hombre moderno, aún con su mejor voluntad, no es capaz de representarse toda la efectiva magnitud del influjo que las ideas religiosas han tenido sobre la conducta en la vida, la civilización y el carácter nacional, nuestra intención no es tampoco sustituir una concepción unilateralmente «materialista» de la cultura y de la historia por una concepción contraria de unilateral causalismo espiritualista. Materialismo y espiritualismo son interpretaciones igualmente posibles, pero como trabajo preliminar; si, por el contrario, pretende sustituir el término de la investigación, ambas son igualmente inadecuadas para servir la verdad histórica» ${ }^{87}$. Por tanto, es cierto que Weber no es un idealista a lo Comte, y que en ese sentido, su libro no se opone al materialismo histórico, sino que, de alguna manera, lo completa ${ }^{88}$. Zeitlin insiste, pues, en que es un disparate pensar que la Reforma fue la causa del capitalismo occidental y que lo que Weber «quiere significar, como se aclara en sus ensayos posteriores, no es que el capitalismo no habría surgido sin él (el espíritu racional-ascético) (...), sino más bien que la forma peculiarmente enérgica que asumió en cierto período histórico podría atribuirse a la afinidad electiva entre los preceptos éticos del protestantismo ascético y el espíritu del capitalismo, donde el énfasis recae en el espíritu. Hubo una coincidencia tan grande entre ambos, que se reforzaron mutuamente para dar origen a una metódica devoción al trabajo y a la actividad empresaria, y, así, a un vigoroso desarrollo del capitalismo»" ${ }^{89}$. Sólo así es inteligible la tesis de Weber para Zetlin, pero no que la ética protestante ejerció una influencia causal fundamental en la creación del espíritu del capitalismo.

Vemos, pues, como hay dos interpretaciones de la obra de Weber. Una que se acerca al esquema causalista unidireccional y pretende desprestigiar.la tesis del materialismo histórico, y otra que intenta «suavizar», en todo lo posible, el pensamiento de Weber en aquellos puntos que pueden comprometer la tesis marxista. Las contraposiciones ideológicas de fondo están claras.

Pero por encima de estas discusiones, creo que debemos reconocer que mientras que para Marx el factor últimamente determinante era el económico, para Weber, junto a otras posibles causas, jugaba un papel destacado la ética ascética del puritanismo. Un párrafo, ya citado, de nuestro autor lo refleja con claridad: «Hemos procurado poner de relieve los motivos fundamentales del hecho y el modo de su actuación en sólo un punto, el más importante cier-

87. Max WeBER, La ética..., 260-262.

88. En esta línea afirma M. Hill: «Mejor seria afirmar que Weber explicita lo que Marx dejó implícito, es decir, la función psicológica de los sistemas de creencias, con lo que podríamos decir que comprueba y rectifica, no que suplanta las ideas de Marx». Michael HiLL, Sociologíd de la religion, Ed. Cristiandad, Madrid, 1976, 139.

89. I. ZeITLIN, o.c., 141. 
tamente» ${ }^{90}$. Y ello también se refleja en su recurso al «método de la ausencia» cuando desarrolla sus estudios sobre las grandes civilizaciones. Por otro lado, una lectura atenta del ensayo que comentamos, descubre cómo Weber no desaprovecha «ocasión» para atacar el peligro del «economicismo» de la tesis marxista ${ }^{91}$.

Pero en su afán por defender al marxismo, Zeitlin, como decíamos antes, no se contentó con lo afirmado hasta ahora, sino que pretendió prácticamente anular la tesis de Weber, apoyándose, para ello, en las críticas de otros autores. Así nos recuerda cómo Ephraim Fischoff ha criticado que el método del tipo ideal lleva el peligro de cometer parcialidades, «como en la selección de los conceptos de "vocación» y "predestinación» y en el énfasis puesto en ellos» ${ }^{92}$. Y si difinió el capitalismo haciendo hincapié en su carácter racional y ascético «no halló mucha dificultad en descubrir elementos de coincidencia con la construcción esquemática de la ética protestante, inclinada en la misma direccion" ${ }^{93}$. Critica también este autor el que al considerar los componentes culturales, debería haber sopesado la posible causalidad o influencia en todas las direcciones. Lo planeó Weber, pero no lo hizo nunca.

También cita Zeitlin las críticas que se le han hecho a Weber en relación con los hechos históricos: «En su obra Anfänge des Kapitalismus (Los comienzos del capitalismo), Lujo Brentano sostiene que muchos de los desarrollos que Weber atribuyó al protestantismo ascético ya habían aparecido durante el Renacimiento; y otros estudiosos, en particular R.H. Tawney, han admitido que «la crítica de Brentano según la cual el pensamiento político del Renacimiento fue un solvente tan poderoso de las restricciones comerciales como las enseñanzas de Calvino, no carece de peso". Otros historiadores también han objetado la atribución de Weber de valores antitradicionales principalmente, si no de manera exclusiva, al protestantismo ascético. Han sostenido que esos valores estaban mucho más generalizados de lo que nos hacen creer los ensayos de Weber y que eran tan comunes a los escritores católicos como a los protestantes» ${ }^{94}$.

Por otro lado, como Weber escogió como ejemplos del Calvinismo a Baxter, Wesley, etc. ${ }^{95}$ y no a pensadores de la primera fase del Calvinismo, «Weber parece pasar por alto (...) el grado en que las propias opiniones religiosas fueron afectadas por los desarrollos económicos y políticos» ${ }^{96}$.

90. Max WebER, La ética..., 260.

91. Cf. Max Weber, La ética..., 50, 68-69; nota 36 de 223; nota 40 de 224; nota 83 de 245.

92. I. Zeitlin, O.c., 149.

93. E. Fischoff, The Protestant Ethic and the Spirit of Capitalism: The History of a Contraversy, en Social Research, XI, 1944, 61-67; cit. I. ZEITLIN, o.c., 149.

94. I. ZeITLIN, o.c., 149-150.

95. I. Zeitlin, O.c., 150.

96. Richard BAXTER (1615-1691); John WESLEY (1703-1791); etc., etc. Todos vivieron cien años o más después de Calvino. 
Por último, Zeitlin trae a colación la dura crítica llevada a cabo por Kurt Samuelsson ${ }^{97}$. Este autor viene a decirnos que, en parte, es cierto que los países protestantes fueron más poderosos económicamente que los países católicos, pero las regiones no revelan la simetría que Weber sostuvo. Además «por la época en que nacieron Lutero y Calvino, los Países Bajos y los distritos del norte y el oeste de Alemania ya se habían caracterizado, durante un mínimo de tres o cuatro siglos, por una actividad económica de excepcional efervescencia; había manufacturas y comercio textiles en Holanda y Flandes, y fundiciones de hierro, secaderos de sal y comercio internacional en los territorios hanseáticos. También en Inglaterra la vida económica había comenzado a manifestar gran dinamismo mucho antes de que Enrique VIII pidiera la anulación de su primer matrimonio" ${ }^{98}$. En Suiza, antes que el calvinismo hay que destacar y señalar su situación privilegiada para el comercio entre Italia y el sur y oeste de Europa y la debilidad de los vínculos feudales. Y tampoco en Alemania, según Samuelsson, hay una relación fácilmente perceptible entre el protestantismo y el desarrollo económico, y sí, en cambio, otros factores altamente significativos como «los depósitos de hierro y carbón del Oeste, las rutas comerciales a lo largo del Rhin, la extensión y el rendimiento de la agricultura en el este y el sur" ${ }^{99}$. Samuelsson sostiene, pues, que el capitalismo se desarrolló antes de que el calvinismo llegase a ser religión predominante en el siglo XVII. Es decir, Samuelsson y Zeitlin creen que en Alemania, como en otros lugares (Nueva Inglaterra), el desarrollo económico se puede explicar de manera aceptable sin recurrir al fenómeno religioso.

Junto a estas críticas, Samuelsson también cuestiona la validez de la in-. terpretación de las estadísticas llevada a cabo por Martin Ofenbacher en Baden , por no tener en cuenta la proporción en que estaban representadas las distintas sectas en los diferentes distritos escolares. La mayor cantidad de ninos protestantes «obedecía totalmente al hecho de que vivían más protestantes que católicos en los distritos en que había Realgymnasien, Hobere Bürgerschulen y Realschules» ${ }^{100}$. Para terminar, tampoco está de acuerdo con el supuesto ascetismo de los puritanos de Nueva Inglaterra. Según Gabriel Kolko ${ }^{101}$, historiador norteamericano, la «alegría de vivir» no estuvo ausente de los hugonotes en Carolina del Sur desde que se establecieron a fines de s. XVII. Y lo mismo ocurrió en N. York y Filadelfia. Se desarrollaron actividades no productivas para robustecer el prestigio social. Por otro lado, el capitalismo de Nueva Inglaterra se parecía más al tipo de capitalismo político espe-

97. Kurt SAMUElsson, Religion and Economic Action, Estocolmo; Scandinavian University Books, 1957.

98. Kurt Samuelsson, o.c., 103; cit I. Zeitlin, o.c., 150.

39. 1. ZeITLIN, o.c., 151.

100. K. Samuelsson, o.c., 142; cit. I. Zeitlin, o.c., 153.

101. Gabriel Kolko, Max Weber on America: Theory and Evidences, en Studies in the Philosophy of History, George H. Nadel, comp., N. York: Harper and Row, 1965. 
culador que al racional y sobrio, y se daba una falta de planificación en el tráfico comercial. Además, el trabajo no era tan «libre» como en el esquema téorico de Weber, pues no era extraña la figura del sirviente contratado. A todo ello habría que añadir, según Kolko, que la imagen ascética del Franklin que dio Weber, debía ser corregida en honor a la verdad. Weber seleccionó excesivamente los escritos de este último, desdibujando su auténtica personalidad: la propia de un fisiócrata en grado mayor de lo que creyó Weber, aparte de que su vida fue más «alegre» de lo que nuestro autor supuso.

En definitiva, todas estas críticas socavaron de base, para Zeitlin, la tesis de Weber ${ }^{102}$.

Frente a estas críticas, debemos de hacer las siguientes puntualizaciones:

$\left.1 .^{\circ}\right)$ Con relación a Fischoff, hay que considerar que el intento de Weber es parcial, y que ciertamente la causalidad «en la otra dirección» completaría el esquema de la investigación; pero ello, en principio, no invalida la tesis de Weber correctamente entendida: que la ética protestante fue un factor o condición que favoreció el desarrollo del capitalismo. Por otro lado, el temor de Fischoff sobre los peligros del esquematismo del «tipo ideal», en el caso de Weber, lo creemos infundado. Nuestro autor es consciente de que su concepción del «espíritu del capitalismo» es una construcción ideal a la que la realidad se acerca «asintóticamente», y de que todo fenómeno social implica la incidencia de una pluralidad de factores.

$2^{\circ}{ }^{\circ}$ Sobre los posibles errores históricos, carezco de los conocimientos históricos adecuados para discutir las críticas de Samuelsson o Brentano en detalle, pero no debemos de olvidar lo siguiente: Weber sabía, como buen historiador y economista, que el origen causal del capitalismo no estaba exclusivamente en la ética ascética puritana, aunque éste fuera un factor importante en el terreno histórico. El capitalismo fue el fruto de muchos factores y

102. Recordemos también la crítica de la profesora polaca María Ossowska, la cual sostiene que aunque la tesis historica de Weber acerca de la correlación entre el desarrollo del capitalismo y las virtudes puritanas, resulta, en alguna medida, convincente, resulta más dudosa su aserción psicológica. Con relación a ésta, «no está claro por qué se cree que las virtudes puritanas fomentan el espíritu del capitalismo y especialmente por qué el dogma de la predestinación ha de desempeñar un papel tan importante en ese espíritu. ¿Por qué ha de hacernos creer el dogma de la predestinación que estamos entre los escogidos por el hecho de tener éxito económico en nuestros negocios? La misma conclusión podría sacarse del hecho de sobrevivir en medio de la más completa holgazanería. Precisamente, según los griegos, la creencia en la predestinación dejaría de estimular la actividad y contribuiría, en cambio, a la haraganería (logós argós). En su libro Christianity and morals, Edward Westermarck sefiala certeramente que sólo en determinadas condiciones sociales podría darse la idea de tomar la prosperidad como criterio de pertenencia al grupo de los elegidos.

El dogma de la predestinación es ciertamente muy útil para justificar los propios privilegios y para tranquilizar la conciencia». M. OssowsKa, Para una sociología de la moral, Verbo Divino, Estella, 1974, 159. Es decir, M. OssowSKA cree más probable que el auge del ethos puritano se debiera a su manipulación ideológica por parte de los grupos privilegiados. 
causas, donde cabe señalar sucesos políticos e históricos ${ }^{103}$, los nuevos métodos de cálculo e intercambio comercial, los descubrimientos y el desarrollo científico en general, la ascensión de la burguesía al poder, etc, etc. ${ }^{104}$. Por ello es lógico que las actividadeš económicas comenzaran a desarrollarse incluso antes de la propagación del puritanismo y la ascética reformada. Esto el propio Weber lo admite explícitamente ${ }^{105}$. Ahora bien, la función de este ascetismo fue, eso sí, la de potenciar y favorecer ese desarrollo. Que ese proceso se hubiera desencadenado de todos modos es muy probable, por no decir seguro, pero este factor influyó en la rapidez y características con que lo hizo ${ }^{106}$. De todo esto hay textos de Weber bien explícitos ${ }^{107}$.

3. ${ }^{\circ}$ Con relación a la crítica sobre las estadísticas de Baden, a falta de la posibilidad de una investigación empírica, lo que sí podemos decir es que el interrogante no desaparece: ¿por qué precisamente los protestantes vivían en los distritos donde abundaban centros capacitados para la docencia científicotécnica?, ¿pura casualidad?...

$\left.4 .^{\circ}\right)$ Es cierto que Weber se fija en figuras posteriores del pensamiento reformado. Para nuestro autor, sus escritos son reveladores de un espíritu ascético y de la función que había cumplido, y ello aunque estos autores estuvieron influidos por la corriente secularizadora y hedonista. Weber, aunque consideraba que la concepción calvinista estaba a la base de la moderna concepción económica, reconocía que ésta al desarrollarse había abandonado a aquélla. Los primeros ministros calvinistas procuraban controlar el espíritu hedonista. Pero a medida que el tiempo transcurría, muchos que tuvieron éxitos en los negocios, tendieron a abandonar el calvinismo. Era típico el metodista que se hacía anglicano al conseguir un cierto relieve económico-social. El ascetismo se fue olvidando ${ }^{108}$. Como dice Weber, el ideal de vida puritano

103. El ataque de Venecia a Constantinopla, las Cruzadas, el descubrimiento de América, etc., etc.

104. Cf. Max Weber, Historia económica general, F.C.E., Madrid 1974.

105. «En primer término, hay formas importantes de economía capitalista que son notoriamente anteriores a la Reforma». Max WEBER, La ética..., 107.

106. «El ethos protestante fue una de las fuentes de la racionalización de la vida que contribuyb a formar lo que se llama el «espíritu capitalista». No fue la causa única o incluso suficiente del principio capitalismo. Dicho de otra forma, el protestantismo fue un elemento que, si se le suprimiera mentalmente en el sentido de las categorías de la posibilidad objetiva y de la causalidad adecuada, no hubiera impedido el impulso del capitalismo, aunque nos obligaría a concebir su evolución de otro modon. J. FreUnd, o.c., 192-183.

107. Cf. Max WEBER, La ética..., nota 14, 261; Max WEBER, Ensayos de sociologia contemporánea, 328,330-331.

108. «Al infundir en todas las actividades económicas una ética planificadora y autodominio, la ensefianza puritana había dado aliento al éxito mundano, que minaba a su vez el modo de vida ascético», R. Bendix. Max Weber, Amorrortu, Buenos Aires, 1970,78. «...ya no es posible hablar hoy de una conexión necesaria entre ese comportamiento práctico «crematístico y una determinada "concepción unitaria del mundo». Sobre todo, ya no requiere apoyarse en la aprobación de los poderes religiosos; y considera como un obstáculo toda influencia perceptible sobre la vida económica de las normas eclesiásțicas o estatales. «La concepción del mundo» va determina- 
fracasó al no poder resistir la dura prueba de la «tentación de las riquezas». Se cumple, una vez más, la ley de la acción secularizadora de las riquezas: «donde la riqueza aumenta la religión disminuye»" ${ }^{109}$.

5. ${ }^{\circ}$ Respecto a la crítica de M. Osswska diremos: Evidentemente las salidas psicológicas en una situación compleja pueden ser varias. Pero la que presenta Weber para la situación de angustia y soledad propia del creyente calvinista, es bastante comprensible ${ }^{110}$. A nivel práctico-pastoral era funcionalmente necesario escapar a la situación límite planteada por las características de las ideas religiosas. Y probablemente las circunstancias materiales como las teóricas pudieron favorecer la salida que se determinó: por un lado, el desarrollo del trabajo empresarial y por otro la coherencia lógica de que la manera más idonea de agradar a un Dios absolutamente trascendente perc creador, era desarrollar su obra y su reino, y desde luego el progreso producti. vo era una manera de continuar la creación. No podemos olvidar que los intereses motivan directamente a los individuos y que, aparte de las circunstancias materiales, las ideas acerca de la realidad influyen en los intereses así como en los medios que se eligen para su prosecución ${ }^{111}$. En este caso, el interés era la "certitudo salutis», y las ideas calvinistas favorecieron la salida apuntada por Weber y estudiada en los textos de autores reformados.

da por la situación de los intereses político-comerciales y político-sociales. (...) Pero todo esto ocurre en una época en la que el moderno capitalismo ha triunfado ya, emancipándose de sus antiguos asideros». Max WEBER, La ética.... 72. Por estas y el resto de las razones aducidas, nos parece que la crítica de $\mathbf{H}$. Laski es un tanto drástica y desafortunada. Cf. H. LASKI, El liberalismo europeo, F.C.E., México, 31.

109. «Este poderoso movimiento religioso, cuyo alcance para el desenvolvimiento económico consistió ante todo en sus efectos educativos ascéticos, no desarrollo la plenitud de su influencia económica (...) mientras to pasó la exacerbación del entusiasmo religioso, cuando la busca exaltada del reinó de Dios convirtióse en austera virtud profesional, cuando las raíces religiosas comenzaron a secarse y a ser sustituidas por consideraciones utilitarias. (...) Lo que esta época del s. XVII legó como herencia a su sucesora utilitaria fue la exigencia de una conciencia buena (podríamos decir farisaicamente buena) en materia de enriquecimiento, con tal de que éste se realizase en formas legales. Desaparecio todo resto del Deo placere vix potest y nació el ethos profesional burgués». Max W.EBER, La ética..., 251-252.

110. «Parece natural que la consecuencia lógica de la predestinacion fuese el fatalismo. Sin embargo, la consecuencia psicológica fue precisamente la opuesta, en virtud de la idea de la comprobación práctica (...) los electi, precisamente por virtud de si elección son inaccesibles al fatalismo, y justamente en esta repulsa de las consecuencias fatalistas (...) se comprueban a sí mismos». Max WEBER, La ética..., nota 67, 145-146.

111. "Afitmar que las ideas, igual que los factores materiales, pueden generar «intereses» significa que al estudiar las creencias de los puritanos de los siglos XVI y XVII dedicamos nuestra atención a un conjunto de convicciones que son el resultado de una dialéctica interna, al mismo tiempo que guardan cierta relación con los intereses derivados de una cultura material (...) En consecuencia, una vez admitida una determinada visión del universo y del lugar que en el mismo corresponde al hombre - como, por ejemplo, la que propuso Calvino-esta visión generará unos «intereses a partir del momento en que sus adeptos comiencen a elaborar su propia estrategia para la salvacion». Michael HILL, o.c., 141. 
Después de estas consideraciones, no podemos concluir nuestra reflexión final, sino reconociendo que:

A) Una evaluación definitiva del alcance del ethos calvinista en el desarrollo del capitalismo moderno, requiere una profundización en la investigación histórica. Sobre todo de cara a los factores no religiosos y su posible incidencia en los factores religiosos; la parte de la investigación que Weber no llevó a cabo.

B) De algún modo, el ethos calvinista incidió positivamente en el proceso de racionalización económica del mundo moderno.

C) Weber tiene el mérito de haber llamado la atención sobre la importancia que el mundo de los valores y las creencias tiene en el origen y desarrollo de la acción humana y social; lo cual nos debe hacer huir de los reduccionismos simplistas y dogmáticos ${ }^{112}$.

D) La polémica que Weber desencadenó, ha servido, indirectamente, para un análisis crítico y más riguroso del modelo desarrollado por el materialismo histórico y de sus posibilidades operativas.

Manuel FernándeZ del RiEsGo

Universidad Complutense. Madrid

112. Caso típico: una cierta versión del marxismo. Los actuales estudios acerca de países subdesarrollados, ponen de manifiesto que tl desarrollo no depende exclusivamente del trabajo y las inversiones económicas, sino también de otros factores como son las aspiraciones y los valores. 